\title{
Prevalence of autonomic dysfunction among pre-dialysis chronic kidney disease patients in a tertiary hospital, South East Nigeria
}

Obinna Onodugo, Ejikeme Arodiwe, Julius Okoye, Birinus Ezeala, Nkiru Onodugo, Ifeoma Ulasi, Chinwuba Ijoma

University of Nigeria teaching hospital, College of Medicine, Ituku/Ozalla, Enugu, Nigeria, Medicine.

\begin{abstract}
Background: Autonomic dysfunction (AD) has been recognized as an important contributor to the poor outcome in chronic kidney disease (CKD) patients. Several studies have reported abnormalities in heart rate variability (HRV) among these patients. Objectives: To determine the prevalence of Autonomic Dysfunction (AD) in pre-dialysis Chronic Kidney Disease (CKD) patients in a tertiary hospital in South East Nigeria.

Methods: A cross sectional study of eighty chronic kidney disease patients attending the renal unit out-patient in the University of Nigeria Teaching Hospital (UNTH) Enugu was carried out. Forty subjects, drawn randomly, who had no kidney disease served as control. Autonomic function was assessed with non - invasive cardiovascular tests including, measurement of resting tachycardia, orthostatic hypotension, heart rate response (HRR) to standing test, heart rate response to Vasalva manoeuvre and heart rate response to respiration.

Results: With the battery of 5 tests used to assess AD, the frequency of autonomic dysfunction in pre-dialysis chronic kidney disease patients was $51.3 \%$ compared to $7.5 \%$ in the control group. Heart rate response to standing was the most sensitive test to detect $\mathrm{AD}$ in this group of subjects.
\end{abstract}

Conclusion: $\mathrm{AD}$ is a common problem among pre-dialysis CKD patients in Nigeria.

Keywords: Prevalence, autonomic dysfunction, pre-dialysis.

DOI: https://dx.doi.org/10.4314/ahs.v18i4.14

Cite as: Onodugo O, Arodiwe E, Okoye J, Ezeala B, Onodugo N, Ulasi I, Ijoma C. Prevalence of autonomic dysfunction among pre-dialysis chronic kidney disease patients in a tertiary hospital, South East Nigeria. Afri Health Sci. 2018;18(4): 950-957. https:/ / dx.doi.org/10.4314/

ahs.v18i4.14

\section{Introduction}

In Nigeria and other parts of Africa, CKD is a common disease accounting for a significant proportion of patients dying in a typical hospital medical ward ${ }^{1}$. It is a major cause of cardiovascular morbidity and mortality in Nigeria, and most parts of Africa ${ }^{2}$. CKD is an important indirect cause of congestive cardiac failure, and other

\section{Corresponding author: \\ Ejikeme Arodiwe, University of Nigeria teaching hospital, College of Medicine, Ituku/Ozalla, Enugu, Nigeria, Medicine. \\ Email: arodiwenephrol@yahoo.com, ejike.arodiwe@unn.edu.ng}

cardiovascular diseases particularly myocardial infarction, sudden cardiac death, hypertension and stroke. Systolic and diastolic dysfunctions are common in $\mathrm{CKD}^{3}$.

The pathophysiology of cardiovascular disease (CVD) in patients with CKD remains undetermined. Risk factors such as hypertension, diabetes and hyperlipidemia are well recognized as important mechanisms ${ }^{3}$. Other risk factors, including autonomic dysfunction, have now been identified as contributors to the increased CVD in patients with $\mathrm{CKD}^{4}$. Several studies have reported a reduction in heart rate variability (HRV) and the development of complex arrhythmias in $\mathrm{CKD}^{5}$. Autonomic neuropathy as part of uraemic neuropathy has been studied in both pre-dialysis CKD patients and maintenance haemodialysis patients. In pre-dialysis CKD patients, according to earlier reports, autonomic neuropathy is in the order 
of $40-63 \%{ }^{6}$. It is also said to be much more frequent in males than females ${ }^{7}$, more related to severity and duration of $\mathrm{CKD}^{8}$ than the cause of the renal failure. We set out in this study to determine the actual prevalence of autonomic dysfunction in pre-dialysis CKD patients, in a tertiary hospital located in the South Eastern part of Nigeria.

\section{Methods}

We evaluated 80 consenting pre-dialysis CKD patients (stages 3-5), drawn consecutively from the medical out-patient department and medical wards of University of Nigeria Teaching Hospital (UNTH) over a one year period. Patients with severe cardiac disease, cancer, diabetes, collagen and demyelinating diseases, left ventricular systolic dysfunction, or a history of stroke were excluded. All medications with autonomic neuropathy-like symptoms were excluded except the following anti-hypertensive medications: calcium channel blockers, centrally acting anti-hypertensive drugs, diuretics and hydralazine as they are very important components of the patients' medication and we could not afford to withdraw them. This is a limitation to the study. Forty sex and age matched consenting individuals were drawn from amongst medical students, doctors, nurses, hospital staff, patients and patient's relations from the general out-patients dept, without symptoms and signs suggestive of renal failure, diabetes mellitus, or heart disease. The study was approved by the Ethics Committee of the University of Nigeria Teaching Hospital, Enugu, and all subjects signed an informed consent before being included in the protocol.

\section{Study design}

This was a cross-sectional study in which we evaluated autonomic nervous function in patients with $\mathrm{CKD}$ on conservative treatment and compared the results to a control group. Autonomic neuropathy was assessed using a modified Ewing and Clarke's method used by Demir et $\mathrm{al}^{9}$ which consisted of five tests: Resting tachycardia, Heart rate response (HRR) to Vasalva manoeuvre, HRR to deep breathing, HRR to standing, blood pressure response to standing. The parasympathetic function was assessed using resting tachycardia, HRR to Vasalva manoeuvre, HRR to deep breathing and HRR to standing. Sympathetic function was assessed with blood pressure response to standing (orthostatic hypotension). The su- pine blood pressure was taken after 10 minutes of rest, with the cuff of the mercury sphygmomanometer (Accosson model, with standard cuff size $15 \mathrm{~cm} \times 55 \mathrm{~cm})$ applied to the right upper arm of the subject. The approximate systolic blood pressure was obtained by palpation. The cuff was then deflated and re-inflated to about $10 \mathrm{mmHg}$ above the approximate systolic value. Phases I and V Korotkoff's sounds were used for systolic and diastolic blood pressure reading respectively. Electrocardiography (ECG) was done to assess resting heart rate, using a triple lead rhythm strip (Cardiette Autoruler, with facilities for 12 lead electrocardiography). ECG monitoring was done while the patient was lying supine and forcibly exhaling for 10 seconds against a fixed resistance with an open glottis. The patient blew into an improvised sterile mouth piece (Empty $20 \mathrm{ml}$ syringe) attached to a mercury sphygmomanometer maintaining a pressure of $40 \mathrm{mmHg}$ for 10 seconds $^{9}$. The longest and shortest R-R intervals were measured with a ruler. The Vasalva Ratio (VR) was calculated; VR=Longest RR (after the Vasalva manoeuvre)/Shortest RR (During the Vasalva manoeuvre).

The patient was then asked to breathe deeply and regularly at a rate of 6 breaths per minute while sitting up. The electrocardiogram was recorded over three breathing cycles. The average heart rate during deep expiration was subtracted from that during deep inspiration. The average difference found for 6 consecutive inspiration-expiration cycle was taken as the final result ${ }^{9}$. The subject was then asked to stand up from the lying position while the electrocardiogram was recorded. The point of standing was marked on the recording paper. ECG monitoring at a paper speed of $25 \mathrm{~mm} / \mathrm{sec}$ was performed after a rest period in the supine position of 10 minutes, starting from 1 minute before until 30 seconds after the subject started to stand. The ratio of the R-R interval of the $30^{\text {th }}$ beat after standing (in millimetres) to that of the $15^{\text {th }}$ beat was recorded ${ }^{9}$.

Blood pressure of the subject, obtained as already described above, was recorded after 10 minutes of supine rest and after 2 minutes in the standing position. If standing was followed by a reduction in systolic blood pressure of at least $20 \mathrm{mmHg}$ or in diastolic blood pressure of at least $10 \mathrm{mmHg}$ within 3 minutes, orthostatic hypotension was accepted to be present ${ }^{9}$.

Other values obtained during the procedure were inter- 
preted as follows': Heart rate response to Vasalva manoeuvre; Normal $\geq 1.21$, borderline $=1.11-1.20$, abnormal $\leq 1.10$ Heart rate response to deep breathing: Normal $\geq 15 \mathrm{bpm}$, borderline $=11-14 \mathrm{bpm}$, abnormal $\leq 10 \mathrm{bpm}$. Heart rate response to standing: Normal $\geq 1.04$, borderline $=1.01-1.03$, abnormal $\leq 1.01$. Resting tachycardia: Heart rate $\geq 100 /$ minute, at rest.
The values for the autonomic function tests are as shown in table 1. Each normal test was scored 0, a borderline test was scored $1 / 2$ and an abnormal test was scored 1 . The 5 test results were summed up with a maximum total score of 5. A total score of 3 and above was considered evidence of autonomic neuropathy ${ }^{10}$.

Table 1: Values of Autonomic Function Test (Adapted from Demir et al (9).

\begin{tabular}{|c|c|c|c|}
\hline Test & Normal(0) & Borderline(1/2) & Abnormal (1) \\
\hline $\begin{array}{l}\text { HRR to standing } \\
(30 / 15 \text { ratio })\end{array}$ & $\geq 1.04$ & $1.01-1.03$ & $\leq 1.0$ \\
\hline $\begin{array}{l}\text { HRR to deep breathing } \\
\text { (Max.-Min. beats/min) }\end{array}$ & $\geq 15$ & $11-14$ & $\leq 10$ \\
\hline $\begin{array}{l}\text { HRR to Vasalva manoeuvre } \\
\text { (Vasalva ratio) }\end{array}$ & $\geq 1.21$ & $1.11-1.20$ & $\leq 1.10$ \\
\hline Resting Tachycardia & $<100$ & & $\geq 100$ \\
\hline Orthostatic hypotension & $\begin{array}{l}<20 \text { systolic and } \\
<10 \text { diastolic }\end{array}$ & & $\begin{array}{l}\geq 20 \text { systolic or } \\
\geq 10 \text { diastolic or both }\end{array}$ \\
\hline
\end{tabular}

\section{Laboratory evaluation}

Venous blood was collected from the subjects without using a tourniquet. The results of the following tests were obtained from the patients: Serum electrolytes - sodium, potassium, chloride, bicarbonate, calcium, phosphate, serum urea and creatinine, fasting blood glucose and 2 hours post- prandial glucose estimations, packed cell volume. For serum calcium and phosphate estimation, serum calcium - phosphate product above $55 \mathrm{mg} / \mathrm{dl}$ was taken as abnormal and reflective of $\mathrm{CKD}^{11}$. An auto analyzer was used to analyze the blood for serum electrolytes, urea and creatinine. The GFR was estimated using the Cock- roft $/$ Gault formula ${ }^{12}$ : GFR $=[140-$ Age (years) $] \mathrm{x}$ weight $(\mathrm{kg})] / 0.8 \mathrm{X}$ serum creatinine $(\mu \mathrm{mol} / \mathrm{l})$. For women, this was multiplied by a factor 0.85 to get the GFR.

Abdominal ultrasound for kidney sizes and echo texture was also done.

The diagnosis of CKD was based on the Kidney Disease Outcomes Quality Initiative of the National Kidney Foundation (KDOQI/ NKF); eGFR $<60 \mathrm{ml} / \mathrm{min} / 1.73$ $\mathrm{m}^{2}$ and/or at least one marker of renal parenchymal damage (e.g., proteinuria), present for a period of $\geq 3$ months ${ }^{4}$. 


\section{Data analysis}

The SPSS version 11.5 statistical software was used for data analysis. For continuous variables, mean value and standard deviation were calculated and the mean compared using independent t- test. Categorical variables were compared using the non-parametric tests - chisquare. All tests were two tailed with $\mathrm{p}<0.05$ taken as statistically significant.

\section{Results}

\section{Demographic data}

The age and sex distribution was similar in both CKD and control groups (table 2). Most of the patients and control subjects were within the age range of 20-49 years, especially between 20-29 years. There were 39 male and 41 female patients giving a male to female ratio of 1:1.05.
There were 21 male and 19 female control subjects giving a male to female ratio of 1.1:1. They were properly matched as there was no statistically significant difference among them.

In the CKD group, 30/80 patients were in stage 3 (37.5\%; mean eGFR equal to $\left.44.3 \pm 7.6 \mathrm{ml} / \mathrm{min} / 1.73 \mathrm{~m}^{2}\right), 32 / 80$ patients were in stage 4 (40\%; mean eGFR equal to 22.5 $\pm 4.2 \mathrm{ml} / \mathrm{min} / 1.73 \mathrm{~m}^{2}$ ), and $18 / 80$ patients were in stage $5(22.5 \%$; mean eGFR equal to $13.3 \pm 2.5 \mathrm{ml} / \mathrm{min} / 1.73$ $\mathrm{m}^{2}$ ). In the control group, the mean eGFR was $90.6 \pm$ $24.4 \mathrm{ml} / \mathrm{min} / 1.73 \mathrm{~m}^{2}$.

Aetiologies of CKD were chronic glomerulonephritis 41 (51.25\%), hypertensive nephropathy 21 (26.25\%), obstructive uropathy $7(8.75 \%)$, undetermined cause 6 (7.5\%), autosomal dominant polycystic kidney disease 3 (3.75\%), and chronic pyelonephritis $2(2.5 \%)$.

Table 2: Age and sex distribution of patients and control

\begin{tabular}{lclllllllll}
\hline Age & Patient & $\begin{array}{c}\text { Male } \\
\mathrm{N}(\%)\end{array}$ & $\begin{array}{l}\text { Female } \\
\mathrm{N}(\%)\end{array}$ & $\mathrm{X}^{2}$ & $\mathrm{P}$ & Control & $\begin{array}{l}\text { Male } \\
\mathrm{N}(\%)\end{array}$ & $\begin{array}{l}\text { Female } \\
\mathrm{N}(\%)\end{array}$ & $\mathrm{X}^{2}$ & $\mathrm{P}$ \\
\hline$<19$ & 2 & 0 & $2(2.5)$ & & & 1 & 0 & $1(2.5)$ & \\
$20-29$ & 19 & $9(11.25)$ & $10(12.5)$ & & & 14 & $8(20)$ & $6(15)$ & \\
$30-39$ & 17 & $6(7.5)$ & $11(13.75)$ & & & 11 & $6(15)$ & $5(12.5)$ & & \\
$40-49$ & 15 & $9(11.25)$ & $6(7.5)$ & 5.736 & .333 & & & & \\
$50-59$ & 17 & $8(10)$ & $9(11.25)$ & & & 7 & $3(7.5)$ & $4(10)$ & & \\
$60-69$ & 10 & $7(8.75)$ & $3(3.75)$ & & & 3 & $2(5)$ & $1(2.5)$ & & \\
Total & 80 & $39(48.75)$ & $41(51.25)$ & & & 40 & $21(52.5)$ & $19(47.5)$ & & \\
\end{tabular}

$* \mathrm{~N}-$ Number of cases.

\section{Age and sex distribution of patients with autonomic neuropathy.}

Table 3 demonstrates the age and sex distribution of patients with autonomic neuropathy. It shows that though more men $22(53.66 \%)$ than women $19(44.34 \%)$ had autonomic neuropathy among the patient population, this was not statistically significant. Patients between the ages of 30-39 and 60-69 were the most affected by autonomic neuropathy, 11(26.8\%). The least affected were patients within the age group 20-29.

Anthropometric and physiologic values for autonomic neuropathy present $(\mathrm{AN}+\mathrm{ve})$ and autonomic neuropathy absent (AN-ve) patients.

African Health Sciences Vol 18 Issue 4, December, 2018 
Table 3: Age and sex distribution in autonomic neuropathy positive patients

\begin{tabular}{llllll}
\hline Age & $\mathrm{M}$ & $\mathrm{F}$ & Total & $\mathrm{X}^{2}$ & P value \\
& $\mathrm{N}(\%)$ & $\mathrm{N}(\%)$ & $\mathrm{N}(\%)$ & & \\
\hline $20-29$ & $4(18.2)$ & $1(5.3)$ & $5(12.2)$ & & \\
$30-39$ & $5(22.7)$ & $6(31.6)$ & $11(26.8)$ & & \\
$40-49$ & $4(18.2)$ & $3(15.8)$ & $7(17.1)$ & 3.939 & .414 \\
$50-59$ & $5(22.7)$ & $2(10.5)$ & $7(17.1)$ & & \\
$60-69$ & $4(18.2)$ & $7(36.8)$ & $11(26.8)$ & & \\
Total & $22(53.66)$ & $19(46.34)$ & $41(100)$ & & \\
\hline
\end{tabular}

Table 4 shows that there are no statistically significant dif- pressure of the patients who had autonomic neuropathy ferences in the mean age, weight, height, BMI, and blood and those who did not.

Table 4: Anthropometric and physiologic values for $\mathrm{AN}+\mathrm{ve}$ and $\mathrm{AN}$-ve patients

\begin{tabular}{|c|c|c|c|c|c|}
\hline \multirow[t]{2}{*}{ Variables } & \multicolumn{2}{|c|}{$\begin{array}{c}\text { AN +ve } \\
\text { Number }(\%) \\
41(51.3)\end{array}$} & \multicolumn{2}{|c|}{$\begin{array}{c}\text { AN-ve } \\
\text { Number }(\%) \\
39(48.8)\end{array}$} & \multirow[t]{2}{*}{$p$ value } \\
\hline & Mean & SD & Mean & SD & \\
\hline Age & 41.81 & 1.38 & 41.11 & 1.54 & .643 \\
\hline Weight & 65.45 & 11.08 & 65.52 & 12.61 & .341 \\
\hline Height & 1.67 & 0.10 & 1.69 & 0.09 & .789 \\
\hline BMI & 23.34 & 3.04 & 22.69 & 2.90 & .721 \\
\hline \multicolumn{6}{|l|}{ Blood pressure } \\
\hline Standing systolic & 140.68 & 18.09 & 147.08 & 17.90 & .968 \\
\hline Standing diastolic & 82.84 & 12.41 & 89.44 & 10.94 & .262 \\
\hline Supine systolic & 146.77 & 17.61 & 146.94 & 16.53 & .754 \\
\hline Supine diastolic & 88.29 & 12.19 & 87.94 & 11.36 & .440 \\
\hline
\end{tabular}

$\mathrm{AN}+\mathrm{ve}=$ Autonomic neuropathy present, $\mathrm{AN}-\mathrm{ve}=$ Autonomic neuropathy absent 
Abnormal autonomic function test in patients and control

Table 5 shows that the frequency of abnormal HRR to standing, breathing, valsalva manoeuvre, and orthostatic hypotension were significantly commoner in the patients compared with controls, $\mathrm{p}<0.001$ for the first three, and 0.014 for orthostatic hypotension. Resting tachycardia did not demonstrate statistical significance, $\mathrm{p}=0.34$. It also showed that $41(51.3 \%)$ of the patients had autonomic neuropathy, while $3(7.5 \%)$ of the controls had it, $\mathrm{p}<$ 0.001 .

Table 5: Frequencies of abnormal autonomic function tests among patients and control.

\begin{tabular}{|c|c|c|c|c|}
\hline $\begin{array}{l}\text { Autonomic function } \\
\text { test }\end{array}$ & $\begin{array}{l}\text { Patient } \\
n=80 \\
\text { N }(\%)\end{array}$ & $\begin{array}{l}\text { Control } \\
n=40 \\
\mathrm{~N}(\%)\end{array}$ & $\mathbf{X}^{2}$ & $P$ value \\
\hline $\begin{array}{l}\text { Autonomic } \\
\text { dysfunction }\end{array}$ & $41(51.3)$ & $3(7.5)$ & 21.979 & 0.000 \\
\hline HRR to standing & $64(80)$ & $19(47.5)$ & 17.592 & 0.000 \\
\hline HRR to breathing & $63(78.8)$ & $5(12.5)$ & 55.767 & 0.000 \\
\hline $\begin{array}{l}\text { HRR to Vasalva } \\
\text { manoeuvre }\end{array}$ & $49(61.3)$ & $3(7.5)$ & 43.757 & 0.000 \\
\hline Resting tachycardia & $16(20.0)$ & $2(5.1)$ & 4.517 & 0.340 \\
\hline $\begin{array}{l}\text { Orthostatic } \\
\text { hypotension }\end{array}$ & $11(13.8)$ & 0 & 6.055 & 0.014 \\
\hline
\end{tabular}

HRR: heart rate response

\section{Discussion}

This study aimed at determining the prevalence of autonomic dysfunction in pre-dialysis CKD patients who are in stage 3 to stage 5 , as dialysis has added autonomic dysfunction to the burden of CKD. The study revealed that autonomic dysfunction is common among predialysis CKD patients in Nigeria with a prevalence of $51.3 \%$.This is similar to some other studies previously done. Sanya in Nigeria reported a prevalence rate of $65 \%$ among CKD patients ${ }^{10}$ while other workers outside Nigeria reported prevalence rates of $40 \%-63 \%$ in predialysis CKD patients. ${ }^{6}$ Demir et al however reported a prevalence rate of 87.5\% among 16 CKD patients already receiving HD. ${ }^{9}$ The high prevalence value reported by Demir et al may be because most of the patients they used in the study had been in stage $5 \mathrm{CKD}$ for a long time, and already getting haemodialysis, a known cause of $\mathrm{AD}$.

When patients with autonomic neuropathy were compared with those without, statistically significant differences were seen in four of the five tests used to assess presence of autonomic neuropathy, table 5. This contrasts to what Demir and colleagues reported. Apart from resting tachycardia which did not demonstrate statistical difference between the patients and the controls, all the other tests used to assess for autonomic dysfunction showed significant differences. In their study however, resting tachycardia was defined as resting heart rate above 
100 beats/min, while resting heart rate of 100 beats/min was included as resting tachycardia in our study. Infact 3 out of 9 of their patients with parasympathetic dysfunction had heart rates of 100 beats per min. ${ }^{?}$

Most of the patients with autonomic neuropathy (95\%) had abnormal heart rate response (HRR) to standing. This was found to be the most sensitive test in detecting autonomic neuropathy. This corresponds to earlier reports by Demir, et al and Sanya. Demir et al recorded abnormal HRR to standing in $87.5 \%$ of their patients with autonomic neuropathy ${ }^{9}$ while Sanya recorded abnormal HRR to standing in $87 \%$ of his patients. However, unlike Demir et al who recorded abnormal HRR to respiration and Vasalva among patients with autonomic neuropathy in the order of $62.5 \%$ and $18.7 \%$ respectively, our study recorded $92.7 \%$ and $85.4 \%$ respectively, while Sanya recorded $61.5 \%$ and $81.8 \%$ respectively. Some of these differences may be explained in part by the fact that the patients used in our study were pre-dialysis patients while Demir et al only used patients on dialysis. ${ }^{9}$ Our work showed that the significance of the HRR tests in descending order is: HRR to standing, HRR to respiration and then HRR to Vasalva. This matched the pattern found in the study by Demir et al, but does not correspond with the findings of Sanya., ${ }^{9,10}$ Sanya found HRR to Vasalva more significant than HRR to respiration.

In our study, resting tachycardia was not found to be significant as a test for autonomic neuropathy. Autonomic dysfunction in CKD patients was not significantly affected by all the anthropologic and physiologic values tested.

The study revealed that CKD commonly involved the young adults, with peak prevalence between the ages of 20-29 years. This is in keeping with the previous observations of relative youth of CKD patients in tropical West Africa. The youths are often in their second and third decades of life, with bilaterally shrunken kidneys and in end stage renal failure. ${ }^{13}$ We noted the slight female preponderance in this study unlike in previous studies. ${ }^{14,15}$ This observation however was not statistically significant.

\section{Study limitation}

The limitation of our study is the inclusion of patients on crucial anti-hypertensive medications that have autonomic neuropathy like side effects. This could be a basis for further study in which these medications could be used as variables and controlled for. Severity of symptoms with medication could also be assessed.

\section{Conclusion}

$\mathrm{AD}$ is a common problem among pre-dialysis CKD patients in Nigeria, with a frequency in pre-dialysis chronic kidney disease patients, of $51.3 \%$. Heart rate response to standing was the most sensitive test to detect AD in this study.

\section{Conflict ofinterest}

None.

\section{References}

1. Adetuyubi A., Akinsanya JB, Onadeko BO. Analysis of the causes of death on the medical wards of University College Hospital, Ibadan over a 14 year period (19601973). Trans Roy Trop Med Hyg. 1977; 70: 466-473.

2. Ogunlesi AO, Philips RE. Acute and chronic renal failure. In:Raine AEG. (ed). Advanced renal medicine, Oxford Med Publishers, 1992; 325-328.

3. Harnet JD, Parfrey PS. Left ventricular dysfunction in dialysis subjects. In: William I.H. (ed.) Principles and practice of dialysis; 1998; 170-180.

4. National Kidney Foundation - K/DOQ1. Clinical practice guidelines for chronic kidney disease: Evaluation, classification and stratification. Am J Kidney Dis. 2002; 39: 546-547,

5. Levey AS. Definition and classification of chronic kidney disease: A position statement from Kidney Disease: Improving Global Outcomes (KDIGO). Kidney Int. 2005; 67: 2089-2100.

6. Zuchelli P, Struvan A, Zuccala A. Dysfunction of the autonomic nervous system in patients with end- stage renal failure. Contrib Nephrol. 1985; 45: 69.

7. Jedras M, Zakraewska- Priewska B, Wardyn K, Switalski M. Is uraemic neuropathy related to patient's age, duration of neuropathy and dialysis treatment. (Polish). Polskie Archiwum medyeyny Wewetrznej 1998; 99 : 452461.

8. Bregman N, Winchester JF, Knepshiel HH, Gelfane MC, Manz HJ, Schreiner GE. Iron overload associated myopathy in patient on maintenance haemodialysis: a histocompatibility linked disorder. Lancet. 1980; 882-885 
9. Demir S, Koken T, Gokce C. Autonomic dysfunction is associated with oxidative stress in non - diabetic haemodialysis patients. Dialysis and Transplantation. 2005; 34:74-115.

10. Sanya EO. Pattern of Autonomic neuropathy in patients with chronic renal failure. FWACP part 11 dissertation, 2002.

11. Tonsello S, Dhupar S, Sherman RA. Phosphate binders, K/DOQ1 Guidelines, and compliance: The unfortunate reality. Dialysis and transplantation. 2004; 33 : 236-291. 12. Oxford Textbook of clinical Medicine; Cameron S,
Davison AM, Grunfeld J, Kerr D, Ritz E.(ed). London. 2000; $1: 35$.

13. Akinsola W, Odesanmi WO, Ogunniyi JO, Ladipo GOA. Diseases causing renal failure in Nigerians - a prospective study of 100 cases. Afr Med J Sci. 1989; 18:131135.

14. Kadiri S, Arije A. Temporal variation and meteorological factors in hospital admissions of chronic renal failure in South West Nigeria. W Afr Med J. 1999; 18: 49-51. PubMed.

15. Schaumbey HH, Spensor PS. Toxic neuropathies. Neurology. 1979; 299: 429-431. PubMed. 